surgery under general anesthesia, were enrolled in a prospective, randomized, double-blind, single-centre, pilot study [NCT04530903].

Group. 1 received an ultrasound-pudendal block using $75 \mu \mathrm{g}$ of clonidine per side; group. $20.5 \mathrm{ml}$ of $\mathrm{NaCl} 0.9 \%$ per side; both groups received $10 \mathrm{ml}$ of levobupivacaine $0,25 \%$.

Primary outcome: total consumption of tramadol in PACU. Secondary outcomes: time between block and first analgesic demand; tramadol request within $24 \mathrm{~h}$; postoperative pain; satisfaction.

Continuous data were compared via T-test or Wilcoxon signed-rank test; means \pm st.deviation or medians are reported. For count data, Pearson Chi-Squared test was performed to compare proportions. $\mathrm{P}<0.05$ was considered significant.

Results Demographics and surgical data were comparable between groups. The groups were not statistically different for the primary outcome (group.1:100 $\mathrm{mg} ;$ group.2:450 mg; $\mathrm{P}=0.1677)$.

$55.6 \%$ of group.2 requested tramadol in PACU $(\mathrm{P}=0.09677)$ compared to $12.5 \%$ of group. 1 .

Within 24h, group.1 required more Tramadol $(\mathrm{P}=0.05)$.

VAS longitudinal analysis showed a group-time effect with significantly higher pain within $24 \mathrm{~h}$ in group. 1 ( $\mathrm{P}=0.0477)$.

Satisfaction was not statically different between groups. Conclusions Adding clonidine to levobupivacaine in pudendal block did not improve postoperative analgesia.

A large-scale study is needed to further support these results.

\section{INFECTION AFTER KNEE ARTROPLASTY, DO WE KNOW ALL RISK FACTORS?}

B Sánchez Quirós*, LH Rocio, PH María Asunción. Hospital Clinico Universitario de Valladolid, Valladolid, Spain

10.1136/rapm-2021-ESRA.231

Background and Aims Non-steroidal anti-inflammatory drugs (NSAIDs) inhibit cycloxygenasa and it causes granulocytic function suppressio (1). These effects could be found in relation to the increased incidence of infections and higher risk of bleeding (2).

Aim of this study was a descriptive analysis of risk factors for total knee arthroplasty, in order to evaluate the relationship between NSAIDs and perioperative infection (4).

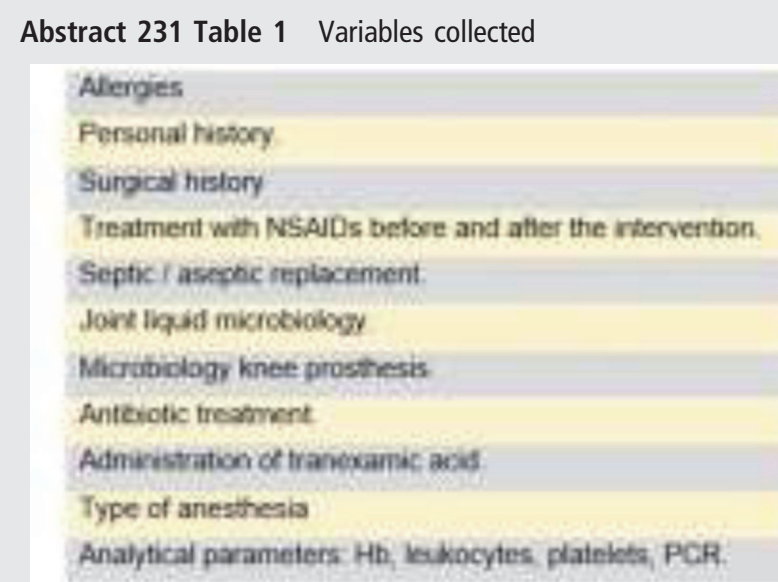

Methods A descriptive observational study in 25 patients medical records who were scheduled for total knee arthroplasty in University Hospital of Valladolid. The following variables were collected (table 1). The study was aprobed by Hospital Clínico

Abstract 231 Table 2 Baseline clinical epidemiological characteristics of the sample

\begin{tabular}{|c|c|}
\hline & Twing \\
\hline Thmon & mas matsi \\
\hline Dowetes Whine & 725064 \\
\hline Hrperiterein & 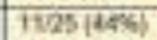 \\
\hline Orexestona & 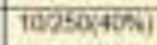 \\
\hline Condepaly & $1025(40 \mathrm{~A})$ \\
\hline Cbestr & 425 (स) \\
\hline 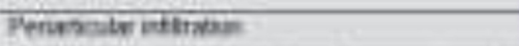 & बहाएका \\
\hline 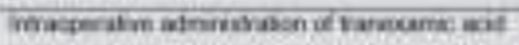 & 1E25 \\
\hline tocuegond areshesia & $23 / 25(2025)$ \\
\hline
\end{tabular}

Abstract 231 Table 3 Distribution of risk factors in both groups (septic/aseptic)

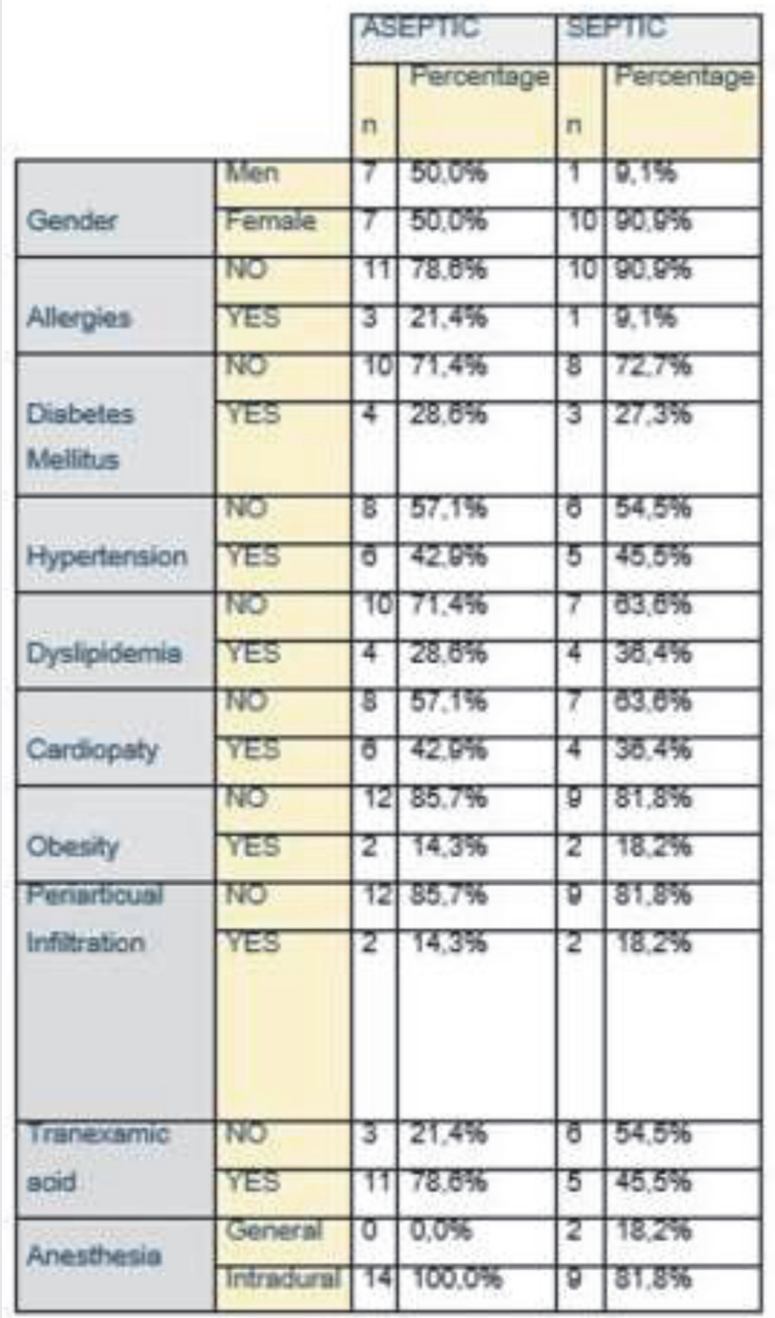


Universitario de Valladolid with number (CEIm PI 19/1438). All patients signed the inform consent to enter the study.

Results Statistically significant differences were found in the rate of infection with respect to sex; being more frequent the infections in the feminine sex $(p=0.042)$. Marginally significant differences were found between the taking of NSAIDs and infection of the prosthesis $(p=0.1)$ although there was no statistical significance between the taking of NSAIDs and the analytical parameters of infection. This study demonstrates that periarticular infiltration does not increase the risk of infection $(p<0.05)$

Conclusions The use of NSAIDs has been associated with an immunosuppressive effect that leads to an increased risk of infection in total knee arthroplasty, so its use in the preoperative period should be limited. Female gender is other significative risk factor too. Our retrospective study has shown relationship between AINEs use and infection after knee arthroplasty.No increased risk of bleeding with AINEs in this sample.

\section{CONTINUOUS ERECTOR SPINAE PLANE BLOCK FOR POSTOPERATIVE ANALGESIA AS AN ALTERNATIVE TO EPIDURAL CATHETER IN THORACIC SURGERY FOR PATIENTS WITH EMPYEMA: A CASE SERIES}

C Simon*, N Parisi, G Samouri. Clinique Saint-Pierre, Ottignies, Belgium

\subsection{6/rapm-2021-ESRA.232}

Background and Aims We present a case series of five patients undergoing video-assisted thoracoscopic surgery for empyema. In this infectious state, we chose to perform a continuous ESP because of the relative contraindication of epidural catheter. We performed it to prevent and relieve the thoracic pain but also to limit the opioids consumption and their side effects in our frailty patients.

Methods The plan was general anaesthesia combined with a continuous unilateral ESP block. Postoperative analgesia was achieved by continuous infusion + bolus of L-Bupivacaine $0.125 \%$. Complementary analgesia was done with paracetamol and when possible NSAID. Patients received iv doses of piritramide in the recovery room, but no patient-controlled analgesia or other intravenous opioids was administered subsequently.

Results Most of the patients maintained a Numeric pain Rating Scale (NRS) between 0 and 3.

We removed the catheters the same day than the pleural drains, usually at day 4 . In the postoperative period, no side

\section{DAILY EVOLUTION OF NRS}

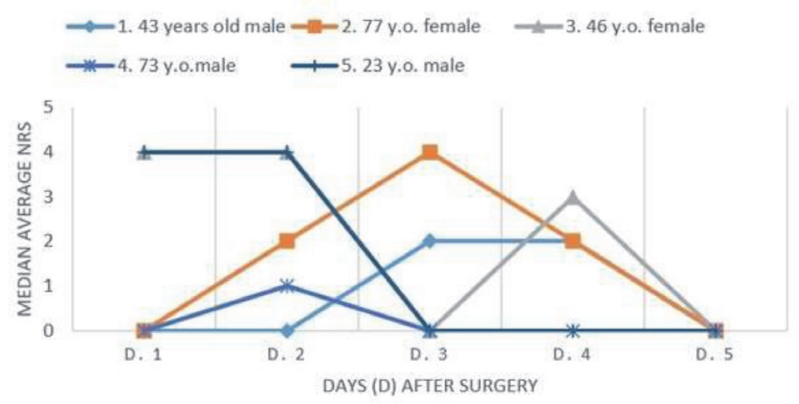

effects (motor blockade, urinary retention or hypotension) were noticed and patients attested high satisfaction scores. We emphasize the fact that none of them requested additional opioids.

Conclusions In cases of empyema, the ESP catheter combined with multimodal analgesia seems to be a safe and effective alternative to epidural analgesia for VATS surgery. This technique, easy to perform, allows an early mobilization of the patient regarding the low pain scores and the absence of side effects. Prospective randomized trials are needed to confirm the benefits of the ESPB compared to epidural or paravertebral bloc.

\section{PECS II BLOCK FOR ONCOLOGIC BREAST SURGERY DURING PREGNANCY: A PATIENT-CENTERED CASE REPORT}

1J Pinho*, ${ }^{2} \mathrm{~J}$ Moita, ${ }^{1} \mathrm{~N}$ Veiga. ${ }^{1}$ Francisco Gentil Portuguese Oncology Institute of Lisbon, Department of Anesthesiology, Lisbon, Portugal; '2Setúbal Hospital Center, Department of Anesthesiology, Setúbal, Portugal

\subsection{6/rapm-2021-ESRA.233}

Background and Aims Anesthesia and analgesia for surgery during pregnancy has focused on avoiding teratogenic drugs, preserving intrauterine homeostasis, and decreasing the risk of preterm labor. Data on the use of regional techniques and on patient preferences are still scarce. Based on a clinical case, we aimed to explore the patient experience of analgesia for oncologic breast surgery during pregnancy.

Methods A 19-weeks-pregnant 40-year-old woman with a diagnosis of breast cancer presented for mastectomy and sentinel lymph node biopsy. After discussion with the patient, an analgesia plan of post-induction pectoral type-2 block, acetaminophen, low-dose morphine, and postoperative acetaminophen, tramadol and prn metamizole was chosen. Acetaminophen and prn metamizole were prescribed home. Patient experience was elicited during the perioperative care and in a semi-structured interview at four-months.

Results On the first postoperative day, the patient reported only mild pain on movement and declined analgesia except for one administration of acetaminophen. After discharge, she reported significant pain on the surgical drain site. Until drain removal on the fourth postoperative day, she took acetaminophen and one prn metamizole. The main themes identified in the patient experience were a prioritization of fetal wellbeing, a concern for the effect of analgesic drugs on the fetus, and apprehension regarding nausea and sedation.

Conclusions Outcomes commonly measured in medical research are ultimately surrogates for outcomes that are more relevant to patients. This case suggests that a decreased need

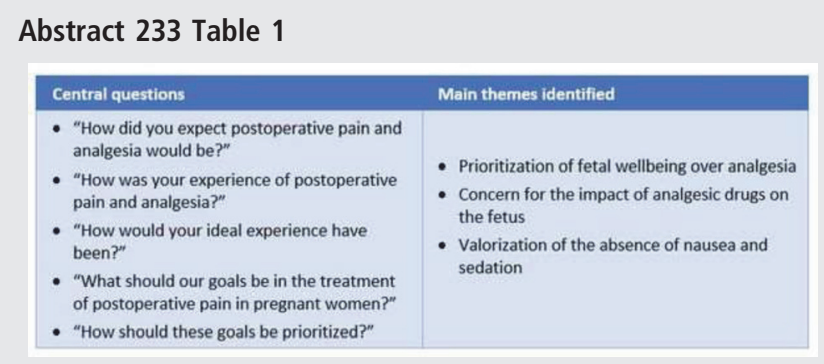

